\title{
Trauma imaging of the cranio-cervical junction: Diagnosis
}

\section{S K Misser, T Z Mngoma, M Roux}

Lake Smit and Partners, Durban

$S$ K Misser, MB ChB, FC RAD (D) SA

T Z Mngoma, MBA, MB ChB, FFRAD (SA)

Entabeni Hospital, Durban

M Roux, MB ChB, FCS (SA)

Corresponding author: S Misser (misser@lakesmit.co.za)

We congratulate Dr Jolandi van Heerden (Neuroradiology Fellow, Neurological Intervention and Imaging Service of Western Australia (NIISWA), Sir Charles Gairdner Hospital, Nedlands, Western Australia) for a most precise diagnosis, for which she receives the award of R1 000 from the RSSA. Drs Misser et al. elaborate below on the condition and its imaging. Please refer to page 120 of the September 2012 issue of the SAJR (http://www.sajr.org.za/index.php/sajr/article/view/773/598) for the presentation details and images.

\section{Diagnosis}

A 5-year-old boy presented to A\&E with quadriparesis after a motor vehicle accident. Initial plain radiographs were normal. The CT images of the cranio-cervical junction (CCJ) obtained on admission showed a large acute prepontine retroclival extradural haematoma (REH). There is posterior displacement of the tectorial membrane and compression of the lower pons and medulla. No fractures of the clivus or the upper cervical vertebrae is noted. The craniocervical junction bony elements retain their normal alignment with preservation of the powers ratio.

MRI sequences performed (including sagittal T1, sagittal T2 and axial T2-weighted sequences) demonstrated the REH compressing the pontomedullary junction of the brainstem. There is also T2-weighted low-signal posterior to the medulla (Fig. 4) in keeping with perimedullary localised subarachnoid haemorrhage. Ventral medullary hyperintensities in the pyramids seen best on the axial T2-weighted image (Fig. 4) are in keeping with oedema. There is no T1-weighted shortening or $\mathrm{T}^{*}$ abnormal signal to indicate contusion. Compression of the vertebrobasilar vessels is noted. Subtle T2 hyperintensity was identified in the upper border of C6 (Fig. 6), suggesting superior end plate marrow oedema from hyperflexion injury.

A diagnosis of tectorial membrane injury associated with REH, venous perimedullary subrachnoid haemorrhage and compressive oedema of the ventral medulla was made. In view of the suspected instability and the size of the REH, surgical internal fixation was undertaken. The child responded very well following surgical fixation and the quadriparesis resolved.

\section{Discussion}

The principal stabilisers of the CCJ are the tectorial membrane, transverse ligament and the alar ligaments ${ }^{1}$ (see Fig. 1). Of these, the tectorial membrane is the most important. Tectorial membrane injury associated with REH is rarely seen. This type of injury occurs most frequently in children following abrupt acceleration/deceleration highvelocity motor vehicle accidents. The consequent CCJ hyperextension/

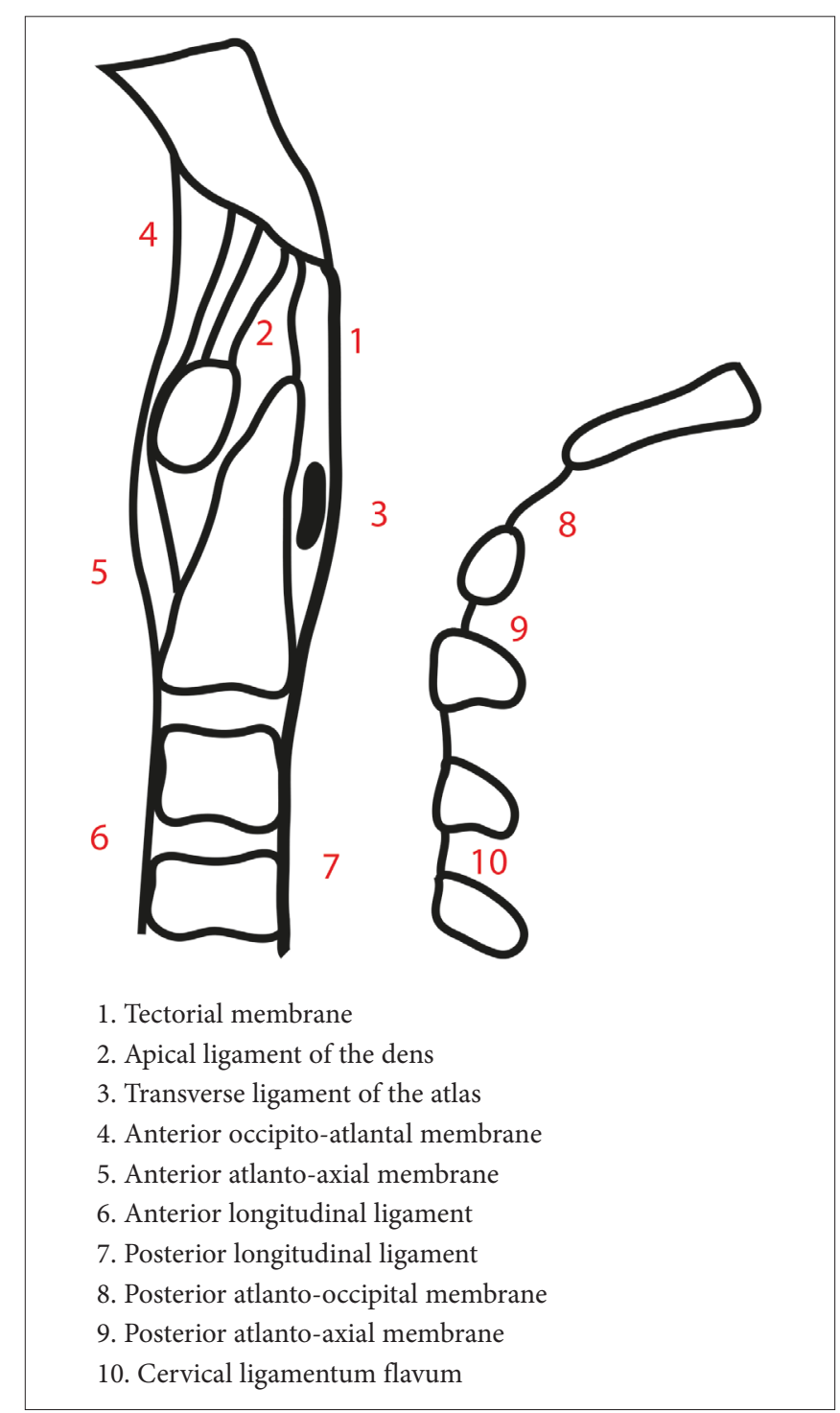

Fig. 1. Sketch showing the key ligaments assessed at the CCJ. 


\section{QUIZ CASE}

hyperflexion is the patho-mechanism resulting in antero-posterior dens subluxation. The poorly adherent dura and ligaments in children are more easily disrupted at the osseo-ligamentous attachment with subsequent prepontine venous plexus damage and REH. There are several reasons why children are more at risk for CCJ injury (Table 1).

\section{Table 1. Factors predisposing to childhood CCJ injury}

Lax ligaments

Large calvarium-to-body ratio

Poorly developed neck musculature

Smaller occipital condyles to support head

Relative CCJ hypermobility

In acute paediatric CCJ injury, MRI is the imaging modality of choice for detailed assessment of the integrity of the ligaments, presence of $\mathrm{REH}$ and relations of the components of the CCJ. Tectorial membrane injury is manifest by discontinuity of the normal T2 hypo-intense signal of the ligament, increase of the T2 signal intensity or if the intact membrane is elevated by a REH. ${ }^{2}$ Complete assessment of the CCJ ligaments must include those listed in Fig 1.

Review of the literature indicates that this entity is under-diagnosed. Suspicion by the treating clinician and equally by the reporting radiologist is crucial. Assessment of children injured in high-velocity traffic accidents usually includes plain radiographs of the cervical spine initially and possibly a CT scan of the brain if there is suggestion of loss of consciousness or decreased alertness.

Radiography in the setting of isolated ligamentous injury of the CCJ rarely yields an abnormality. CT scans focussed primarily on the brain structures and performed after hours with sub-optimal inclusion of the foramen magnum/CCJ area will result in inadequate demonstration of the REH. Only a few of these patients proceed to have MRI studies performed, where direct demonstration of tectorial membrane injury and REH is made possible.

Non-dislocated CCJ injuries without fractures are usually managed conservatively. Injury of the CCJ ligaments including tectorial membrane, inadvertently influences CCJ stability. The decision to proceed to surgical fixation may be influenced by overt MRI features of tectorial membrane disruption or large $(>4 \mathrm{~mm}) \mathrm{REH}$.

It is imperative that the retroclival area be well-included in the CT and MR imaging fields and that the reporting radiologist purposefully adds the CCJ as a review area. ${ }^{2}$

\footnotetext{
1. Benedetti PF, Fahr LM, Kuhns LR, Hayman LA. MR Imaging findings in spinal ligamentous injury AJR 2000;75:661-665.

2. Meoded A, Singhi S, Poretti A, Eran A, Tekes A, Huisman TAGM. Tectorial membrane injury: Frequently overlooked in pediatric traumatic head injury. AJNR 2011;32:1806-1811.
}

S Afr J Rad 2012;16(4):149-150. DOI:10.7196/SAJR.793 